\title{
Segurança, Território, População
}

FOUCAULT, Michel. Segurança, território, população: curso dado no Collège de France (1977-1978). São Paulo: Martins Fontes, 2008 (Coleção tópicos).

EDSON BENEDITO RONDON FILHO

\section{Resumo}

A obra retrata o curso de mesmo nome ministrado por Michel Foucault no Collège de France (1977-1978), onde o autor desenvolveu a genealogia de uma forma de saber político centrado nos mecanismos que possibilitam a regulação da população. A arte de governar e o 'governo de si' são questionados em um transcurso histórico que desaguou em uma "razão de Estado", cuja racionalidade implicou na construção de conjuntos de saberes e de tecnologias de poder, necessários para o crescimento das forças do Estado. Ao demonstrar os problemas que a Polizeiwissenschaft devia controlar, delimitou o papel da polícia como garantidora da ordem interna e técnica de controle populacional, dotada de saberes específicos, constituindo-se, junto com segurança e a Economia Política, naquilo que Foucault denominou de biopolítica.

Palavras-chave: Biopoder. Segurança. Governamentalidade. Polícia. Razão de Estado.

\footnotetext{
* Cientista Social, Bacharel em Direito, Mestre em Educação e Doutorando em Sociologia pelo Programa de Pós-graduação em Sociologia do Instituto de Filosofia e Ciências Humanas (IFCH) da Universidade Federal do Rio Grande do Sul (UFRGS).
} 
Em Poitiers, França, nasceu Paul-Michel Foucault (1926), licenciado em psicologia e filósofo de formação pela Sorbonne (1949). Intitulou-se pirotécnico (Droit, 2006, p. 69) por entender que seu pensamento não era teórico e sim constituído de erupções que possibilitam refletir sobre uma realidade obscurecida por discursos e transformada pelos interesses inclusos nas teias relacionais de poder. Sua obra é extensa, mas inacabada, devido ao seu falecimento prematuro em 1984.

Foucault entendia que a realidade não pode ser percebida de maneira natural em razão das suas constituições históricas. Sua proposta de corte epistemológico reside justamente em romper com o pensado e se questionar em como podemos lutar e combater uma ordem discursiva imposta pela trama relacional de poder (Eizirik, 2005, p. 15)

A obra Segurança, Território, População (1978) é a consubstanciação da publicação do curso intitulado na mesma nomenclatura e ministrado no Collège de France, com início em 11 de janeiro de 1978 e término em 05 de abril do mesmo ano, em um total de 13 (treze) aulas, onde ele analisa a gênese de um saber político voltado para o controle da população por mecanismos de regulação matizados no biopoder.

Biopoder é conceito que ele já havia utilizado em História da sexualidade, retomado nos seguintes termos: “(...) o conjunto dos mecanismos pelos quais aquilo que, na espécie humana, constitui suas características biológicas fundamentais vai poder entrar numa política, numa estratégia política, numa estratégia geral de poder" (Foucault, 2008, p. 3). É assim que ele o considera (biopoder) como sendo uma das configurações da governamentalidade que transforma a vida em objeto de poder.

Para o desenvolvimento de sua análise apresenta cinco indicações: 1) não propor nenhuma "teoria geral do que é o poder" (...), mas "do poder, contanto que se admita que o poder não é, justamente, uma substância, um fluido, algo que decorreria disto ou daquilo" (idem, p. 4), ou 
seja, sua primeira opção é analisar a mecânica do poder e não o que é o poder; 2) analisar os procedimentos emergidos nas relações que estabelecem, mantêm e transformam os mecanismos de poder; 3) mostrar pelas lutas, pelos choques e pelos combates quais são os efeitos do saber produzidos na sociedade através dos mecanismos de segurança; 4) propor imperativos condicionais, vistos como indicadores táticos, que embasem o círculo da luta e da verdade; 5) propor um único imperativo categórico e incondicional, qual seja, "nunca fazer política"1.

Em seguida, Foucault lança uma série de questões para definir "segurança" no sentido mediano de eventos criminais com interferentes no funcionamento social, apresentando três formas: 1) o sistema código penal; 2) a lei e os mecanismos de vigilância e correção e o mecanismo disciplinar; 3) o dispositivo de segurança. É esse dispositivo de segurança que em determinado tempo histórico, depois de fixar a média dos eventos, estabelece o que é aceitável. Para ele, não há um único mecanismo determinante, mas, sim, situações em que seus edifícios se intercambiam, interagindo e alterando as técnicas, havendo sim “(...) correlação entre os mecanismos jurídicos-legais, os mecanismos disciplinares e os mecanismos de segurança" (idem, p. 11).

Foucault deixa claro que na sua visão a soberania se exerce em um território, a disciplina tem como alvo o indivíduo, e a segurança, por sua vez, é exercida sobre a população (idem, p.16). A disciplina atua em um espaço vazio ao passo que a segurança se acosta em materialidade. Para essa análise, utiliza o exemplo da 'cidade' e de como se deu o planejamento do que poderia 'circular' ou 'não circular' no seu interior, através dos 'controles reguladores' que possibilitaram vida e saúde às populações.

\footnotetext{
1 Michel Senellart apõe nas notas de referências da edição resenhada que essa frase deve ser comparada com a que Foucault declarou a D. Trombadori, durante uma longa entrevista concedida, na qual manifestou sua decepção em razão das polêmicas teóricas dos movimentos de extrema-esquerda depois de Maio de 1968.
} 
Em específico, ao analisar a circulação dos cereais, Foucault identifica no século 18 uma nova concepção da economia apresentada pelos fisiocratas, que, através do princípio da circulação, funcionou como consequência de um campo teórico e este, por sua vez, implicou em mudança nas tecnologias de poder. É assim que se instala o dispositivo de segurança "(...) e não mais um sistema jurídico-disciplinar" (idem, p. 49). A escassez como justificativa de medidas interventivas no território transforma-se em quimera e a morte dos indivíduos passa a ser tolerada. A população converte-se em objetivo do dispositivo de segurança enquanto o indivíduo se torna objeto instrumental. A política disciplinar é vista de forma centrípeta e a de segurança, de forma centrífuga (idem, p.59).

Adiante, ele realiza uma comparação entre a lei, a disciplina e a segurança para diferenciá-las, apontando que a primeira (lei) proíbe, a segunda (disciplina) prescreve e a terceira (segurança), sem proibir ou prescrever, anula, limita ou regula uma realidade através de alguns instrumentos de proibição e de prescrição (idem, p. 61). Na lei, há uma normatividade que a relaciona à norma, mas que não se configura em técnica de normalização. A normalização é conseguida pela disciplina que estabelece procedimentos e demarca o que é normal e o que é anormal, sendo preferido por Foucault, nesse caso, o termo 'normação' em vez de normalização. Na segurança, o normal vem primeiro e dele se deduz a norma, aí sim ocorre a normalização (idem, p. 62-83).

A Maquiavel, Foucault tece crítica vertida na linha daquilo que ele denominou de "fim de uma era", ou seja, a obra O príncipe retrata o ápice de um momento em que o problema era a segurança do príncipe e do seu território. Para Foucault, o problema que se apresentava era outro e se ligava à população e aos governantes que viam essa população, naquele momento, não mais como força produtiva e sim como objeto técnico-político (idem, p. 82-92). O texto segue uma linha genealógica 
da "ciência do bem governar" envolta no 'governo de si' e no governo da família. É com a população que o governo pode ser pensado fora da soberania, sendo a família alvo e instrumento de controle do bom governo. Ressalta, entretanto, que a soberania não é eliminada, ocorrendo sim o denominado triângulo: soberania, disciplina e gestão governamental.

O conceito de governamentalidade é apresentado como forma de poder que tem como saber a economia política e por instrumento os dispositivos de segurança (idem, p. 143). Ela não é a mesma coisa que 'reinar', 'comandar' ou 'fazer a lei', está ligada à arte de governar e para sua compreensão deve-se: 1) reconstruir as relações que a permeiam de maneira global a fim de tentar encontrar as técnicas de poder; 2) passar para o exterior dessas tecnologias e se ressituar nesta economia de poder; 3) apreender o movimento das tecnologias de poder vistas na relação poder-saber (idem, p. 157-158). Esse governo não é exercido sobre o Estado, o território ou uma estrutura política, mas sim sobre as pessoas, os indivíduos, os homens e as coletividades (idem, p. 164).

Nessa análise do ato de governar, Foucault foca seu olhar no poder pastoral, em um primeiro momento, apontando sua gênese no Oriente pré-cristão, caracterizando-o como uma relação entre Deus e os homens e, em um segundo momento, comparando-o com a Grécia Antiga, faz um percurso na transição do pastorado para o governo político. Para analisar a presença do poder pastoral na Grécia, Foucault usa três grupos de referências: 1) o vocabulário homérico; 2) a série de textos de tradição pitagórica; 3) os estudos do alemão Gruppe, que defendia a tese de que a metáfora do pastor não existe na Grécia, salvo nas regiões de influência hebraica, e a tese de oposição proposta por Delatte, o qual renegava a questão do pastorado a lugar menor (idem, p. 165 e 195).

Para Foucault, o pastorado só foi existir e se configurar de fato com o cristianismo, sendo dispositivo de poder preponderante durante quase 
15 séculos (desde os séculos 2, 3 d.C. até o século 18 d.C.). As guerras religiosas desse período (batalhas pastorais) foram lutas pelo direito de governar e não questão doutrinária como se tenta passar, a exemplo da Reforma e da Contrarreforma. No entanto, o poder pastoral e o poder político conservaram suas próprias especificidades e fisionomias, apesar das interferências mútuas, apoios e intermediações, e isso se converteu em um enigma para Foucault (idem, p. 196 e 216).

Foucault, em seguida, argumenta que o pastorado cristão foi o pano de fundo do processo da governamentalidade do Estado moderno e que ela (pastoral) está relacionada com três coisas, a saber: 1) a salvação, fundada na lógica do mérito e do demérito; 2) a lei, que vai consubstanciar a servidão; 3) a verdade, revelada por meio do pastor. Isso deu azo ao regime das almas, incidente sobre todas as comunidades cristãs e sobre o indivíduo cristão em particular (idem, p. 217 e 252).

$\mathrm{Na}$ aula de 1 o de março de 1978, Foucault analisa as formas de resistência ao poder pastoral com três observações a fazer: 1) a toda lei apresentada pode-se responder por infrações sistematizadas; 2) essas revoltas têm especificidade e não se confundem com as revoltas políticas ou econômicas; 3) os conflitos de conduta ganham o campo político, como: a) fazer a guerra; b) desenvolver-se sociedades secretas; c) dissent médico contra o saber instituído. Essa resistência, Foucault nominou de contraconduta, identificando algumas na Idade Média, como: 1) o ascetismo; 2) a formação de comunidades que questionaram o poder sacramental; 3) a mística em algumas experiências que fogem ao controle pastoral; 4) a escritura que passa a desconsiderar a presença de intérpretes; 5) a crença escatológica que, por assim dizer, dispensa os pastores já que Cristo está voltando. Esses elementos-fronteira foram utilizados tanto pela Reforma como pela Contrarreforma, interferindo diretamente no poder pastoral. Aqui temos uma observação muito importante ao pensamento de Fou- 
cault, pois se desprezarmos essas articulações do poder pastoral que opôs e intercambiou as crises econômicas com os temas religiosos, estaremos presos às velhas concepções de ideologia e imposição de uma ideia dominante de um grupo ou classe dominante (idem, p. 253 e 303).

É nesse mosaico político, cujo marco temporal se dá nos séculos 17 e 18, que a diferenciação entre o que é público e o que é privado vai se estabelecer, ditando o que seja da ordem estatal e sujeito aos instrumentos de controle, fundamentando a razão governamental, vista por Foucault como intensificação do pastorado religioso. É a separação entre a natureza e o Estado, “(...) entre os principiae naturae e a ratio status" (idem, p. 319), que irá possibilitar manter e conservar o Estado dentro de uma racionalidade. $\mathrm{O}$ autor lembra que o Estado aqui compreendido é aquele que entrou na prática refletida dos homens, uma vez que as instituições que o compõem, como os exércitos e o fisco, datam de bem antes do século 16. O golpe de Estado não é visto como confisco, mas sim como a afirmação da razão de Estado que se automanifesta para salvar o Estado, independentemente dos instrumentos utilizados, mesmo que seja necessário desconsiderar as leis em vigor e exceder o direito natural (idem, p. 349/351). Ou seja, a razão de Estado pode se converter em golpe de Estado de maneira violenta e mortífera, inclusive, sacrificando alguns em benefício do Estado. Seu reconhecimento deve ser imediato e demanda certa teatralidade em face de sua representação.

O cálculo passa a ser outro, agora focado nos elementos da economia com reflexos na opinião, objetivando evitar e coibir as sedições, apostas por Foucault e embasadas no pensamento de Bacon como materiais (indigência e descontentamento) e ocasionais (por exemplo, mudança de religião, modificação de privilégios, subversão das leis, entre outros). O equilíbrio político está no cálculo dos riscos para que o Estado se mantenha rico - em recursos e em possibilidades comerciais - e forte nas 
concorrências estabelecidas. A conservação dessa dinâmica de forças é o verdadeiro problema dessa racionalidade governamental que, para sua consubstanciação no Ocidente, exigiu a criação do dispositivo diplomático-militar e do dispositivo de polícia, possibilitando a balança europeia nas suas três definições: 1) impossibilidade de um Estado mais forte ditar as regras para os demais; 2) limitação na criação de Estados fortes; 3) “(...) a força preponderante de um ou vários países seja igual à força reunida dos outros", ou seja, “(...) a reunião de várias pequenas potências possa contrabalançar a força da potência superior, que poderia vir a ameaçar uma delas" (idem, p. 397 e 401).

É em nome desse equilíbrio que as guerras se justificam e a concepção diplomática de sociedade das nações é formulada, surgindo o dispositivo militar, dotado de uma lógica adequada à razão governamental, para equalização da relação guerra e paz (idem, p. 402 e 410).

Quanto ao dispositivo de polícia, Foucault começa explicitando algumas observações a destacar: 1) o sentido da palavra ("polícia"); 2) as relações entre os problemas do equilíbrio da balança da Europa e a definição da polícia; 3) a necessidade dessa força nos Estados como arte comum constitutiva de seu crescimento. Da ocupação da polícia, destacam-se: 1) a instrução das crianças; 2) a caridade dos pobres e a saúde pública; 3) o favorecimento do comércio; 4) os registros dos bens imobiliários. Em suma, a polícia é instrumento de crescimento da força estatal e tem uma função utilitária nesse crescimento ao se ocupar, nessa nova razão de Estado: 1) com o número de habitantes; 2) com as necessidades da vida; 3) com os problemas de saúde; 4) com a ociosidade dos homens. Assim, a coexistência entre os homens torna-se objeto da polícia (idem, p. 419 e 448).

A polícia, para Foucault, é um feixe de relações ajustada ao princípio de governar para gestão da população e da produção se constituindo em golpe de Estado permanente, pois ela não se molda às regras de 
justiça ditadas por outro lado. Para a polícia, o mundo é regulamentar e essencialmente urbano (idem, p. 449 e 459).

O abalo desse sistema policial dá-se por quatro teses: a primeira se funda no pensamento fisiocrático sobre a circulação dos cereais, o que estoura os limites do sistema policial - estabelecido no setor urbano quando a terra e a agricultura passam a ser problema; a segunda tese é a da inutilidade dos regulamentos policiais no equilíbrio dos preços que deveria se dar de forma espontânea; a terceira tese é a de que a população deixa de se constituir em um bem e adquire um valor relativo; a quarta tese é a de que a concorrência entre Estados cede lugar à concorrência econômica entre os particulares, cujo objetivo principal é o lucro máximo. É a razão econômica que agora dará as linhas da governamentalidade moderna, onde a razão de Estado sofre uma alteração renegando a racionalidade de polícia ao controle dos súditos. Ao mesmo tempo, a relação entre o poder e o saber se converte em fundamento de decisão, e a população passa a ser vista como um conjunto de fenômenos que devem ser controlados para possibilitar o crescimento do Estado. A polícia se torna responsável pelo impedimento de desordens (idem, p. 460 e 469).

Temos assim que o pensamento foucaultiano possibilita compreender a articulação entre a força social e o Estado, no caso em questão, a passagem da governamentalidade de polícia para a governamentalidade de segurança, que é a configuração mais geral de poder na sociedade moderna. A base epistêmica consiste, justamente, em governar conforme a nova governamentalidade, cujos elementos são: sociedade, economia, população, segurança e liberdade (idem, p. 470 e 477).

O devir histórico de autorregulação da sociedade, da economia, da população, da segurança e da liberdade é a proposta de Foucault que vê nesse transcurso histórico formas de contracondutas, como: 1) a afirmação de que a sociedade civil prevalecerá sobre o Estado; 2) o direito à 
revolução; 3) oposição à ideia de que o Estado é o detentor da verdade (idem, p. 478 e 480).

Finaliza o curso fazendo uma crítica ao método empregado na pesquisa, afirmando que a história do Estado deve ser feita através da prática dos homens, pois entre o nível de micropoder e o nível do macropoder não existem cortes, o que os faz associados em qualquer análise que se faça de um ou de outro (idem, p. 481).

O livro é o exemplo de como Foucault suspendeu as evidências para dizer que as coisas existem, utilizando para tanto uma geometria variada. A teoria empregada por ele não possui ponto de partida, nem sujeito e nem liberdade, pois o que existe são relações. O que está em jogo é o procedimento de suspensão das evidências dos objetos pré-constituídos e como eles são constituídos em grades de inteligibilidade.

Trata-se de uma leitura imprescindivel aos cientistas sociais e profissionais das áreas afins que pretendam ter contato com uma forma caleidoscópica de ver o mundo, colocando em suspensão as evidências ditadas por determinada ordem discursiva, as quais anularam as percepções antagônicas.

\section{Security, Territory, Population (Lectures at the College de France)}

Review: FOUCAULT, Michel. Segurança, território, população: curso dado no Collège de France (1977-1978). São Paulo: Martins Fontes, 2008 (Coleção tópicos).

\section{Abstract}

The work depicts the course of the same name delivered by Michel Foucault at the Collège de France (1977-1978), where the author has developed the genealogy of a political knowledge centered on the mechanisms that enable to control people. "The government of the self and others" are questioned along a 
historical course that resulted in a "reason of State", whose rationality entailed in the construction of sets of knowledge and technologies of power, necessary for the growth of State forces. In explaining the problems that the Polizeiwissenschaft should control, he defined the role of the police as a guarantor of internal order and as a technique for controlling people, invested with specific knowledge, and which constitutes, along with the security and the political economy, what Foucault called biopolitics.

Keywords: Bio-power. Security. Governmentality. Policy. Reason of State.

\section{Referências}

DROIT, Roger-pol. Michel Foucault, Entrevistas. Tradução de Vera Portocarrero e Gilda Gomes Carneiro. Rio de Janeiro: Graal, 2006.

EIZIRIK, Marisa Faermann. Michel Foucault: um pensador do presente. $2 \stackrel{a}{a} \mathrm{ed}$. rev. ampl. ljuí: Editora Unijuí, 2005.

FOUCAULT, Michel. Segurança, território, população: curso dado no Collège de France (1977-1978). Tradução Eduardo Brandão. São Paulo: Martins Fontes, 2008.

Recebido em: 14/04/2011

Aceite final: $12 / 08 / 2011$ 